\title{
Study on the Systemic Risk of China's Stock Markets under Risk-Neutral Conditions
}

\author{
Shibo Dai, Handong Li \\ School of Systems Science, Beijing Normal University, Beijing, China \\ Email: lhd@bnu.edu.cn
}

How to cite this paper: Dai, S.B. and $\mathrm{Li}$, H.D. (2019) Study on the Systemic Risk of China's Stock Markets under Risk-Neutral Conditions. Journal of Mathematical Finance, 9, 54-79.

https://doi.org/10.4236/jmf.2019.91005

Received: January 4, 2019

Accepted: February 24, 2019

Published: February 27, 2019

Copyright $\odot 2019$ by author(s) and Scientific Research Publishing Inc. This work is licensed under the Creative Commons Attribution International License (CC BY 4.0).

http://creativecommons.org/licenses/by/4.0/

(c) (i) Open Access

\begin{abstract}
Based on stochastic discount factor theory, this paper proposes a method to convert the traditional systemic risk measures of financial markets, such as VaR, ES, MES and SES, into risk-neutral measures. We proposed a novel way to neutralize the returns without relying on option price information. Then, we empirically analyzed and compared the systemic risks and changes between the A-shares in Shanghai and $\mathrm{H}$-shares in Hong Kong before and after a stock market crash, and we found that systematic risk measures under risk neutrality could more accurately determine market system risks than traditional systemic risk measures. Moreover, these systemic risk measures have a certain market risk warning effect.
\end{abstract}

\section{Keywords}

Stochastic Discount Factor, Risk Neutrality, Tail Risk, Shanghai Index, Hang Seng Index

\section{Introduction}

Systemic risk is the most important risk that must be faced and managed in the financial market. For example, in the 2014-2015 stock market disaster in China and the Hong Kong stock market crash, the Shanghai 50 Index fell from 3303 to 2376 in a short period of 10 days. The Hong Kong Hang Seng Index dropped from 28,524.6 points in May 2015 to 19,594.6 in December 2015, and the decreasing amplitude reached $28.1 \%$ and $31.3 \%$, respectively. With the development of financial globalization, various extreme events in financial markets have forced financial institutions to shift their attention from day-to-day financial market fluctuations to extreme events. Risk managers also have to identify and guard against such changes caused by the events. They remodel the financial risks by using the events to achieve the goal of optimizing the risk management 
system. This has also made the research of financial systemic risk a hot topic in academic and industry circles.

Financial risk managers usually divide risk into two categories: moment-based risk measures and quantile-based risk measures. Since market investors generally believe that the probability of a left tail event (i.e., a sharp drop in price) is much greater than the probability of a right tail event (i.e., a sudden increase in price), risk managers are most likely to follow the classics, such as [1] [2] [3]. What is concerned is the risk that occurs in the left-tail of the distribution of returns. Therefore, the commonly used risk measurement method in risk management is based on quantile-based tail risk metrics, with the value of risk (VAR) and expected losses (ES) as the main representatives. The VAR model is used to measure the maximum possible losses of a certain asset portfolio within a certain holding period and a given confidence interval, and it can comprehensively reflect the risk measurement of a financial asset. Artzner et al. (1999) [4] proposed an axiomatized system for consistent risk metrics that includes the attributes of transformation invariance, subadditivity, positive homogeneity and monotonicity. They point out that only risk metrics that satisfy these four attributes at the same time are consistent risks metrics. However, the VAR model does not have subadditivity, and the ES model compensates for the subadditivity of the VAR model. Furthermore, they propose the conditional risk value CoVAR on the basis of the value-at-risk VAR model to measure the risk spillover effect of individual institutions. [5] and [6] used the CoVAR method to propose a profit distribution model for the entire financial system based on the risk of a particular financial institution, namely, the "bottom-up" approach. Paper [7] proposed the Marginal Expected Shortfall (MES) on the basis of the expected losses of the ES model to reflect the marginal contributions of individual institutions to the systemic risk. Compared to CoVaR's "bottom-up" thinking, MES is concerned with the distribution of the returns of individual institutions when the entire financial system is in crisis. That is, it follows a "top-down" thinking to satisfy the additivity. Paper [8] derived the SES model based on the binary GARCH model and the nonparametric inference of the dynamic MES.

The traditional VAR and ES estimation methods are mainly based on the assumption of the normal distribution in [9] [10]. Since the logarithmic returns of most assets are asymmetric and thick-tailed, they do not obey the normal distribution. Nonparametric methods do not need to assume the statistical distribution of market factor changes and can effectively address asymmetry and thick-tailed features. Therefore, more scholars use nonparametric estimation methods to estimate the VAR and CoVaR [11] [12] [13] [14].

On the other hand, since the actual stock price includes investor enthusiasm, there is a large deviation from the real risk when directly using stock returns to measure risk. In the risk-neutral world, we do not need to consider the statistical income of investors for risk aversion levels, time preferences, or other changes in economic valuations. The expected return rate of all securities is the risk-free in- 
terest rate. Xiao Hui and $\mathrm{Wu}$ Chongfeng (2006) proposed that under the framework of a stochastic discount factor, the theory of asset pricing in modern financial theory can understand many classical problems of modern financial theory in a relatively simple way. Therefore, the stochastic discount factor model is an approximately unified framework of asset pricing theory in recent years. Existing literature has been used to include the tail risk under risk-neutral conditions. Ait-Sahalia and Lo $(1998 ; 2000)$ [15] [16] proposed a risk-based approach to extracting the risk-neutral density of the S\&P 500 Index. These studies emphasize that the risk-neutral information from option prices can provide a VAR-based measure of tail risk. Recently, Paper [17] proposed a model-free index of investor panic based on futures prices and S\&P 500 index options. In the supplemental work by [18], they provided empirical evidence that the jump risk component of the variance risk premium is a strong predictor of future market returns. Based on the S\&P 500 Index Options, Paper [19] pointed out that risk-neutral indicators have a good predictive effect on future market returns. Paper [20] proposed a method to estimate the risk of extreme events.

However, the abovementioned risk-neutral systemic risk measures are based on a sound option market and high-frequency trading data. China has undergone drastic changes in its financial market in the past few years. Market managers and investors urgently need effective ways to manage system risks. At the same time, China has not established basic derivatives and other financial derivatives trading markets, which makes it difficult for us to effectively measure the systematic risks of China's financial markets using the above methods. As far as we know, there is no relevant research.

Based on the stochastic discount factor, this paper proposes a method for conducting systemic risk measurements under risk-neutral conditions. It uses this method to analyze the changes of the systemic risk in China's Shanghai stock market and Hong Kong stock market and compares it with traditional risk measures. The remainder of the paper is organized as follows. The second section is the introduction of the models and methods, the third section is the empirical results, and the final section is the conclusion.

\section{Models and Methods}

\subsection{Common System Risk Measures}

There are currently two commonly used indicators for measuring risk in financial institutions, VAR and ES. The VAR model is used to measure the maximum possible losses of a certain asset portfolio within a certain holding period and a given confidence interval, and it can reflect the risk measurement of a financial asset.

Assuming the income of the asset to be $R$, we define $\mathrm{VaR}=-q_{\alpha}$, where $q_{\alpha}$ is the quotient of the $R$ in $\alpha$.

$$
q_{\alpha}=\sup \{z \mid \operatorname{Pr}[R<z] \leq \alpha\}
$$


where $\alpha$ is usually $1 \%$ or $5 \%$.

The expected shortfall (ES) refers to the expected losses when the income is less than $q_{\alpha}$.

$$
E S_{\alpha}=-E\left[R \mid R \leq q_{\alpha}\right]
$$

Therefore, ES is the conditional expected value when the return is smaller than $q_{\alpha}$. When the income is less than $q_{\alpha}$, the VaR cannot capture the size of the losses at this time. Furthermore, the $\mathrm{VaR}$ of the portfolio is always higher than the VaR of the single asset. Therefore, the ES is usually used to measure the losses under extreme conditions.

In terms of risk management, it is hoped that the possible losses in the financial market will be broken down into the losses contributed by each asset. Therefore, we decompose the returns $R$ of the stock into the sum of the revenue of each group of $r_{i}$ :

$$
E S_{\alpha}=-\sum_{i} y^{i} E\left[R \mid R \leq q_{\alpha}\right]
$$

Assuming that the system contains $N$ companies, we use MES to represent the ith ( $i=1, \cdots, N)$ company's systemic risk contribution and use ES to the measure systemic risk; the ith company's rate of return is defined as $r_{i t}$.

$$
M E S_{i, t}=\frac{\partial E S_{\alpha}}{\partial r_{i t}}=-E_{t-1}\left[r_{i} \mid R \leq q_{\alpha}\right]
$$

Among them, $M E S_{i, t}$ is the marginal expected loss of the ith company, which measures the ability of the ith company to increase the risks of the entire financial system.

Set $S E S^{i}$, the contribution of asset i to the entire financial system, equal to the total systemic risk. When the entire financial system is in crisis $\left(W_{1}<z A_{1}\right)$, the bank's net asset value $w_{1}^{i}$ is lower than the value of standard $z a_{0}^{i}$ :

$$
S E S^{i}=E\left[z a_{0}^{i}-w_{1}^{i} \mid W_{1}<z A_{1}\right]
$$

In addition, the systematic risk of the unit capital is also an important indicator, which is as follows:

$$
\frac{S E S^{i}}{w_{0}^{i}}=\frac{z a_{0}^{i}}{w_{0}^{i}}-1-E\left[\frac{w_{i}^{i}}{w_{0}^{i}}-1 \mid W_{1}<z A_{1}\right]
$$

here, $\frac{a_{0}^{i}}{w_{0}^{i}}$ is the initial leverage ratio, $r_{i}=\frac{w_{i}^{i}}{w_{0}^{i}}-1$ is the return on capital of the ith bank in the next stage, and the conditions of systemic crisis $W_{1}<z A_{1}$ can also be expressed as the market return rate $R$ being less than a certain standard value $C$. Brownless and Engle (2012) set $C$ to be -0.02 , and the market yield of less than -0.02 as a condition for the occurrence of a systemic crisis. From this, we can translate Equation (6) into the following:

$$
\frac{S E S_{t-1}^{i}}{w_{0}^{i}}=z L E V_{t-1}^{i}-1+M E S_{t-1}^{i}
$$


here, $S E S_{t-1}^{i}$ and $M E S_{t-1}^{i}$ indicate the conditional expectations based on time $t$ - 1's information, respectively, and $L E V_{t-1}$ indicates the bank's leverage at time $t-1$. The marginal expected loss MES and the leverage ratio LEV are defined as follows:

$$
\begin{gathered}
M E S_{t-1}^{i}=-E\left[r_{i} \mid R<C\right] \\
L E V_{t}^{i}=\frac{\text { book_asset }{ }_{t}^{i}-\text { book_equity }{ }_{t}^{i}+\text { market_equity }_{t}^{i}}{\text { market_equity }{ }_{t}^{i}}
\end{gathered}
$$

\subsection{Risk-Neutral Systematic Risk Measurement}

\subsubsection{The Theory of Random Discount Factor}

We define $P_{i, t}$ as the price of securities $i$ at time $t$, where $C_{t}$ is the consumption at $t, e_{t}$ is the foreign wealth of investors at $t, \varepsilon_{i}$ denotes the shares of investors in securities $i$, and $X_{i, t+1}$ is the profits and losses of asset $i$ at $t+1$.

$$
\begin{gathered}
C_{t}=e_{t}-P_{i, t} \varepsilon_{i} \\
C_{t+1}=e_{t+1}+X_{i, t+1} \varepsilon_{i}
\end{gathered}
$$

Then, investors always hope to maximize the utility of current consumption and future consumption, That is to say, investors want to maximize the utility function with respect to $\varepsilon_{i}$, we should refer to a conditional expectation at time $t$ and take the utility of your future consumption $E_{t}\left(u\left(C_{t+1}\right)\right)$. This problem can be expressed as follows:

$$
\max U\left(C_{t}, C_{t+1}\right)=u\left(C_{t}\right)+\beta E_{t}\left(u\left(C_{t+1}\right)\right)
$$

where $\beta$ is the subjective time discount factor of investors that balances current consumption and future consumption, $u\left(C_{t}\right)$ denotes the utility, and $E_{t}\left(u\left(C_{t+1}\right)\right)$ is the expectation of future consumption.

To simplify the problem, we can assume that there is only one risky asset, and as long as the expectation is well defined, then the return on the risky asset can be subject to any probability distribution. For the optimization problem of the objective function $\max U$, the Lagrangian rule can be used to solve the problem. The first-order optimal condition of $\varepsilon$ can be obtained as follows:

$$
u^{\prime}\left(C_{t}\right) P_{i, t}=\beta E_{t}\left(u^{\prime}\left(C_{t+1}\right) X_{i, t+1}\right)
$$

For $u(*)$ is monotone concave function, above formula can be rewritten as follows:

$$
\begin{gathered}
P_{i, t}=E_{t}\left(M_{t+1} X_{i, t+1}\right) \\
M_{t+1}=\beta \frac{u^{\prime}\left(C_{t+1}\right)}{u^{\prime}\left(C_{t}\right)}
\end{gathered}
$$

where $M_{t+1}$ is the marginal substitution rate. When the marginal replacement rate is high, the value of future consumption is high. If the return on assets is high, consumers are willing to pay higher prices.

The discount factor of the asset price is usually expressed in the form of re- 
turns. Define $R_{t}$ as the total returns of the asset. Then, it is equal to 1 plus the proportional return, and $R_{t}=\frac{X_{t+1}}{P_{t}}$.

The pricing relationship given is equivalent to the following:

$$
E\left(M_{t} R_{t}\right)=\mathbf{1}
$$

Assuming that there are $N$ risky assets, we can write the discount model as follows:

$$
E\left(M_{t} R_{j, t}\right)=\mathbf{1}
$$

where $R_{j, t}$ is the return of asset $i$.

Therefore, the time series of the logarithmic returns under risk-neutral conditions can be expressed as follows:

$$
R_{i, t}^{Q}=M_{t} R_{t}
$$

The choice of the discount factor itself is an optimization problem. Here, we use the results given by Dimitrios Bisias (2012):

$$
\begin{gathered}
M_{t}=\frac{R_{G}}{\frac{1}{N} \sum_{i=1}^{N}\left(R_{G} R_{A}\right)} \\
R_{G}=\prod_{i=1}^{N} r_{t}^{\frac{-1}{N}} \\
R_{A}=\frac{1}{N} \sum_{i=1}^{N} r_{t}
\end{gathered}
$$

\subsubsection{Application of Random Discount Factor}

When investors have high expectations of the stock's return, they are willing to pay higher prices for this, and thus the stock price inevitably contains investor enthusiasm. This kind of investor expectations can be more clearly reflected in the risk-neutral world. Almeida et al. [21] proposed to use the data of stock prices to predict the tail risk. In this static setting, an admissible SDF is a random variable $m$ for which $E\left(M_{t} R_{i, t}\right)$ is finite and satisfies the Euler equation:

$$
E\left(M_{t} R_{i, t}\right)=\mathbf{1}_{\boldsymbol{k}}
$$

where $\mathbf{1}_{\boldsymbol{k}}$ represents a K-dimensional vector of ones.

Almeida used the method in [21] to find the stochastic discount factor, and then used Equation (15) to find the income in the risk-neutral world $R_{i, t}^{Q}$. We define $T R_{t}^{i}$ as follows:

$$
T R_{t}^{i}=E S\left[R_{i, t}^{Q}-Z_{i, \alpha} \mid R_{i, t}^{Q} \leq Z_{i, \alpha}\right]
$$

where $T R_{t}^{i}$ represents the risk of the $i$ th asset, $Q$ represents the risk neutrality, $\alpha$ is the probability level, and $Z_{i, \alpha}$ represents the quantile of the $i$ th asset. Equation (16) is based on the application of Equation (3), which is the ES model. Since there are many kinds of stocks, we need to reduce the dimensions of stocks. Almeida et al. [21] adopted the principal component analysis method. They can 
treat each of the obtained principal components as an asset, and then use formula (19) to calculate each dimension. By using the tail risk of the principal components, we can get the average of the tail risks of all the obtained principal components, which we can treat as a risk measurement value for the stock market. We define $T R M_{t, h}$ as a risk measurement value for the stock market as follows:

$$
T R M_{t, h}=\frac{1}{n} \sum_{k=1}^{n} T R_{t}^{k}
$$

where $h$ represents the width of the window and $n$ represents the number of principal components selected.

However, since the contribution of each principal component to the whole is different, such a weighted summation is unreasonable. Therefore, we propose a formula for calculating the weighted sum in which the weights are obtained by principal component analysis. The stochastic discount factor can be expressed as follows:

$$
T R M_{t, h}=\frac{1}{\sum_{k=1}^{n} w_{k}} \sum_{k=1}^{n} w_{k} T R_{t}^{k}
$$

where $w_{k}, k=1, \cdots, n$ denotes the weight of the $\mathrm{k}$-th principal component, and it satisfies $\sum_{k=1}^{n} w_{k}=1$.

Furthermore, we expand Equation (19) to obtain two new systemic risk measures:

$$
\begin{array}{r}
T M R_{t}^{i}=\operatorname{MES}\left[R_{i, t}^{Q}-Z_{i, \alpha} \mid R_{i, t}^{Q} \leq Z_{i, \alpha}\right] \\
T S R_{t}^{i}=\operatorname{SES}\left[R_{i, t}^{Q}-Z_{i, \alpha} \mid R_{i, t}^{Q} \leq Z_{i, \alpha}\right]
\end{array}
$$

where $T M R_{t}^{i}$ is a risk measure calculated using the MES model, and $T S R_{t}^{i}$ is a risk measure calculated using the SES model.

To imitate formula (21), we can obtain formulas (24) and (25).

$$
\begin{gathered}
\operatorname{TMRM}_{t, h}=\frac{1}{\sum_{k=1}^{n} w_{k}} \sum_{k=1}^{n} w_{k} T_{M} R_{t}^{k} \\
\operatorname{TSRM}_{t, h}=\frac{1}{\sum_{k=1}^{n} w_{k}} \sum_{k=1}^{n} w_{k} T_{S R}^{k}
\end{gathered}
$$

\subsubsection{Application of Nonparametric Estimation}

As it is difficult to know what kind of distribution the actual financial time series data obeys, we generally use nonparametric kernel estimation methods to fit the true distribution. The nonparametric kernel method can fit a real distribution function under the condition of limited information, and then obtain the VAR estimate. Chen and Tang (2005) proved that the kernel estimator of the distribution function is a uniform estimator of the true distribution function, and the estimator has continuity and conductibility. Below, we give the kernel estimator of the distribution function. 
Suppose $r_{t}=\left(r_{1 t}, \cdots, r_{n t}\right)^{\prime}$, where $r_{i t}(i=1, \cdots, n ; t=1, \cdots, T)$ is the time series sample of the ith risk asset return rate. The sample mean vector and the sample covariance matrices are as follows:

$$
\begin{gathered}
\bar{r}=\frac{1}{T} \sum_{t=1}^{T} r_{t} \\
\Sigma=\frac{1}{T} \sum_{t=1}^{T}\left(r_{t}-\bar{r}\right)\left(r_{t}-\bar{r}\right)^{\prime}
\end{gathered}
$$

The portfolio yield is $w^{\prime} r_{t}$, where $w=\left(w_{1}, \cdots, w_{n}\right)^{\prime}$ is the weight vector. At this time, the sample mean and sample variance are $w^{\prime} \bar{r}$ and $w^{\prime} \Sigma w$, respectively, according to the nonparametric kernels. The estimation method can obtain the nuclear estimator of the distribution function of portfolio returns:

$$
F(Z)=\frac{1}{T} \sum_{t=1}^{T} K\left(\frac{-w^{\prime} r_{t}+z}{h}\right)
$$

where $K(u)=\int_{-\infty}^{T} k(t) \mathrm{d} t, k(t)$ is a kernel function, and the commonly used kernel functions include uniform kernel functions, Gauss kernel functions, Epanechnikov kernel functions, etc. According to [22], the kernel estimation of the distribution function is not sensitive to the choice of the kernel function. In practice, the Gauss kernel function usually gives a more robust estimation result. That is, $k(t)$ is the density of the standard normal distribution. Parameter $h$ is the width of the window and is generally established using the rule of thumb:

$$
h=1.06 * T^{-0.2} * \sqrt{\sum w^{\prime} w}
$$

The advantage of the nuclear density estimation is to fully utilize the information of the data itself, to avoid the subjective knowledge brought in by the subjective person and to maximize the approximation of the sample data with respect to parameter estimation.

\section{Empirical Analysis}

\subsection{Data and Processing}

In this paper, we use the daily returns of the 20 constituent stocks of the Shanghai 50 Index of the Shanghai Stock Market and the 31 constituent stocks of the Hong Kong stock market Hang Seng Index to conduct the empirical research. The market data of the Shanghai Stock Market is from the Wind database (the leading financial data service provider in China, its market share in China is $80 \%$. Wind database has built a comprehensive database of the most complete and accurate financial and financial data warehouses with financial and financial data as the core) from January 1, 2014, to December 31, 2016. We screened the daily data of the stocks of the Shanghai 50 Index after it was recaptured. From 2014 to 2016, due to the company's major restructuring, stock increase and mergers and acquisitions, etc., the company will stop the company, resulting in the lack of data. After eliminating the stocks that caused the missing data due to these events, in Shanghai 50 Index, we can obtain daily data on 20 stocks as we 
can see in Table 1 . Take 2015 daily data as an example, there are 244 daily closing price data for each stock in the year. The names of the stocks and their codes are as follows:

First, we use the daily closing price $P_{t}$ to obtain the log yield $r_{t}$, where $t=2, \cdots, T$.

$$
r_{t}=\log \left(\frac{P_{t}}{P_{t-1}}\right)
$$

We analyzed the daily returns of these 20 stocks. Figure 1, respectively, shows the return curves and normal distribution test results of 4 stocks, namely, CITIC Securities, Huaxia Bank, Baosteel Co., Ltd. and Minsheng Bank.

From Figure 1, it shows the return curves and normal distribution test results of 4 stocks, namely, CITIC Securities, Huaxia Bank, Baosteel Co., Ltd. and Minsheng Bank. We can see that the price of the stock is random walking.

In this paper, the critical value of the Kolmogorov-Smirnov test in Table 2 is 0.05 . From Table 2 , the sig is less than 0.05 , we can see that the logarithmic returns of the four stocks do not satisfy the normal distribution. This further validates the rationality of using nonparametric tests to process stock data.

Table 1. Table type styles.

\begin{tabular}{cccc}
\hline Stock Name & Stock Code & Stock Name & Stock Code \\
\hline CITIC Securities & 600030 & Conch Cement & 600585 \\
Baosteel Co., Ltd. & 600019 & Daqin Railway & 601006 \\
Huaxia Bank & 600015 & China Shenhua & 601088 \\
Minsheng Bank & 600016 & ABC & 601288 \\
Shanghai Port Group & 600018 & China Ping An & 601318 \\
Sinopec & 600028 & Ban of Communications & 601328 \\
China Unicom & 600050 & ICBC & 601398 \\
Northern Rare Earth & 600111 & China Pacific Insurance & 601601 \\
Guizhou Maotai & 600519 & China Life Insurance & 601628 \\
China Petroleum & 601857 & China Architecture & 601668 \\
\hline
\end{tabular}

Table 2. The normal test results of the daily distributions of 4 stocks.

\begin{tabular}{ccccccc}
\hline & \multicolumn{3}{c}{ Kolmogorov-Smirnov } & \multicolumn{3}{c}{ Shapiro_Wilk } \\
\cline { 2 - 7 } & Statistics & Df & Sig & Statistics & Df & Sig \\
\hline CITIC Securities & 0.112 & 243 & 0 & 0.954 & 243 & 0 \\
Huaxia Bank & 0.118 & 243 & 0 & 0.957 & 243 & 0 \\
Baosteel Co., Ltd. & 0.14 & 243 & 0 & 0.95 & 243 & 0 \\
Minsheng Bank & 0.137 & 243 & 0 & 0.952 & 243 & 0 \\
\hline
\end{tabular}



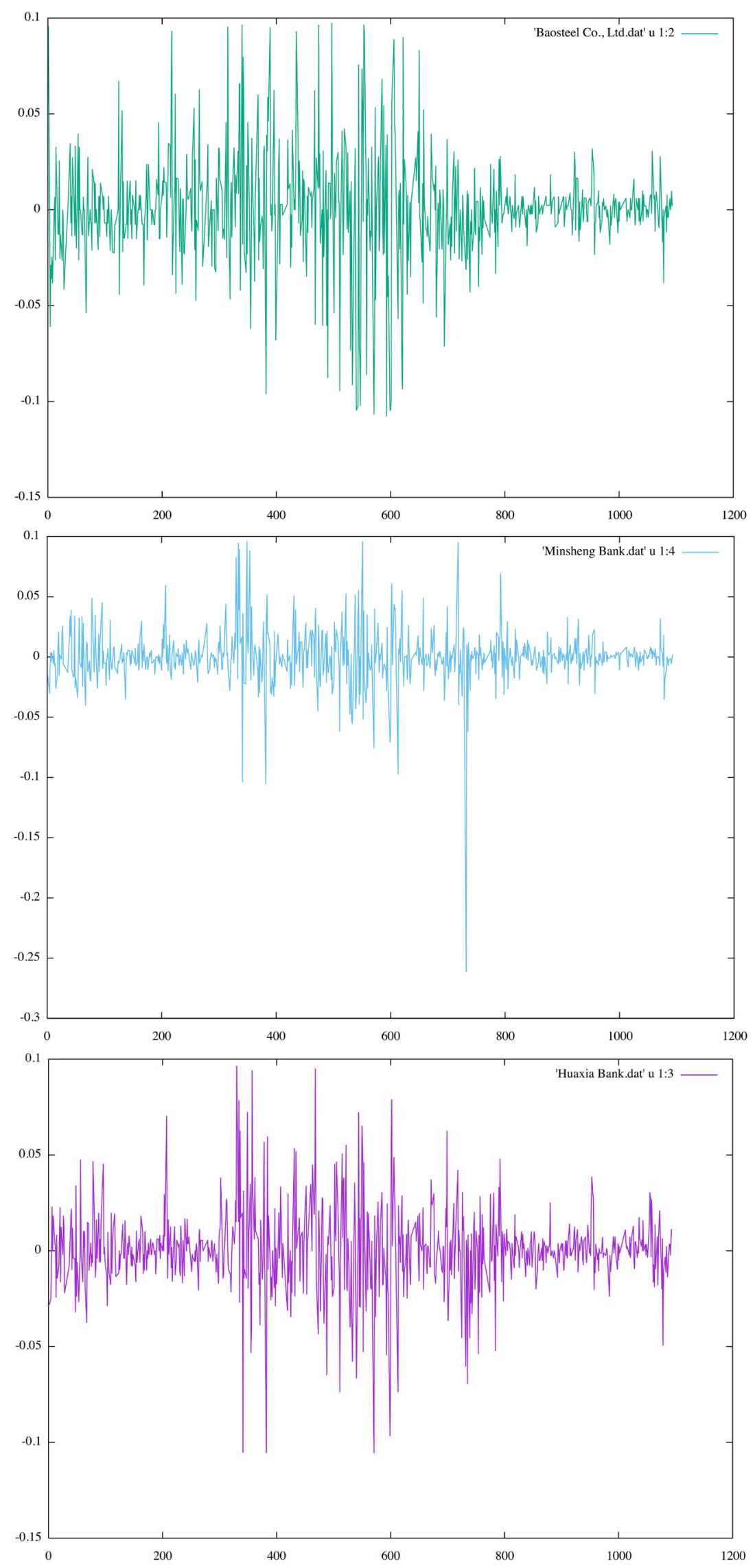


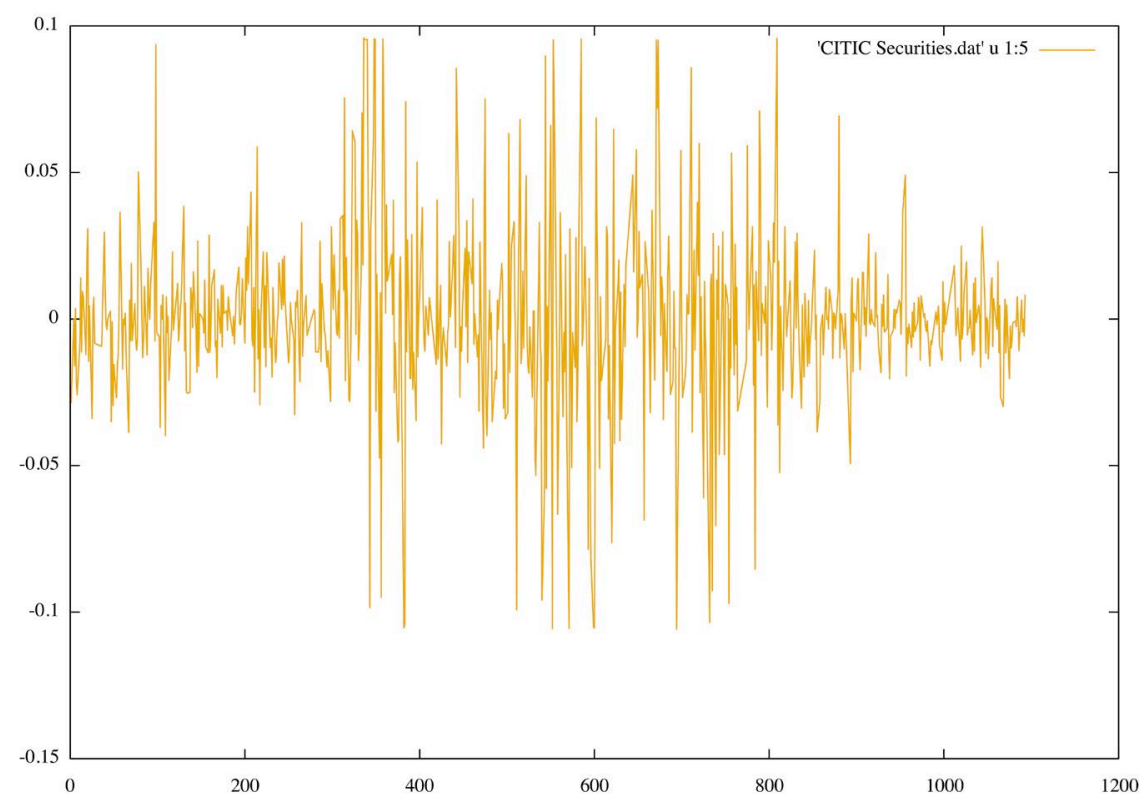

Figure 1. Scatter plot of the actual logarithmic gains.

\subsection{Empirical Analysis of China's Shanghai Stock Market}

\subsubsection{Principal Component Analysis (PCA) of 20 Stocks in the Shanghai Market}

First, we analyze the principal component of the daily logarithmic return sequence of 20 stocks. Figure 2 shows the cumulative interpretation ratio of each principal component to the total variation.

The abscissa of Figure 2 represents each principal component. Each rectangle represents the strength of the explanatory power of each principal component. The larger the rectangular area, the stronger the explanatory power of the factor. According to PCA, the index variables related to each other are converted into index variables that are not related to each other. There are a total of 20 stocks with logarithmic gains corresponding to 20 irrelevant principal components. The vertical axis represents the explanatory power of each principal component. The rectangular region in Figure 2 represents the explanatory force of each different principal component, and the trapezoidal line corresponds to the cumulative sum of the explanatory forces of the principal component. In the component analysis method, the selected principal component meets the requirement as long as the cumulative ability to interpret the original data reaches $70 \%$ or more.

From Figure 2, we can see that if we select the first five principal components, we can explain more than $80 \%$ of all the data. Therefore, we choose five principal components here. At this point, we can treat the time series of each principal component as a variable in order to achieve the effect of dimension reduction. Then, we can use Equations (15)-(18) to find the corresponding risk-neutral discount factor and calculate the logarithmic returns of the five factors under risk-neutrality. Figure 3 gives the scatter plots of the five factors in risk neutrality and actual data. 


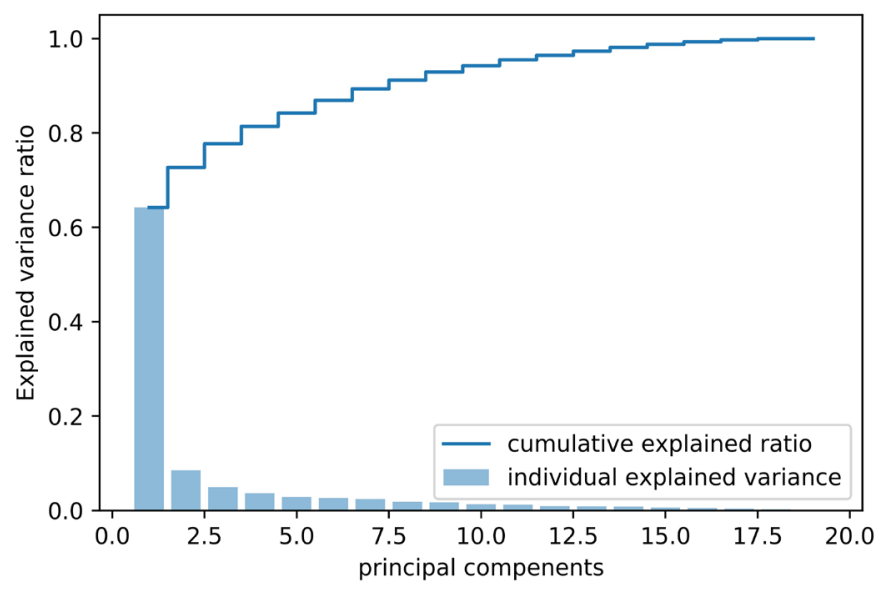

Figure 2. PCA of the 2015 daily returns of 20 Shanghai SSE stocks.
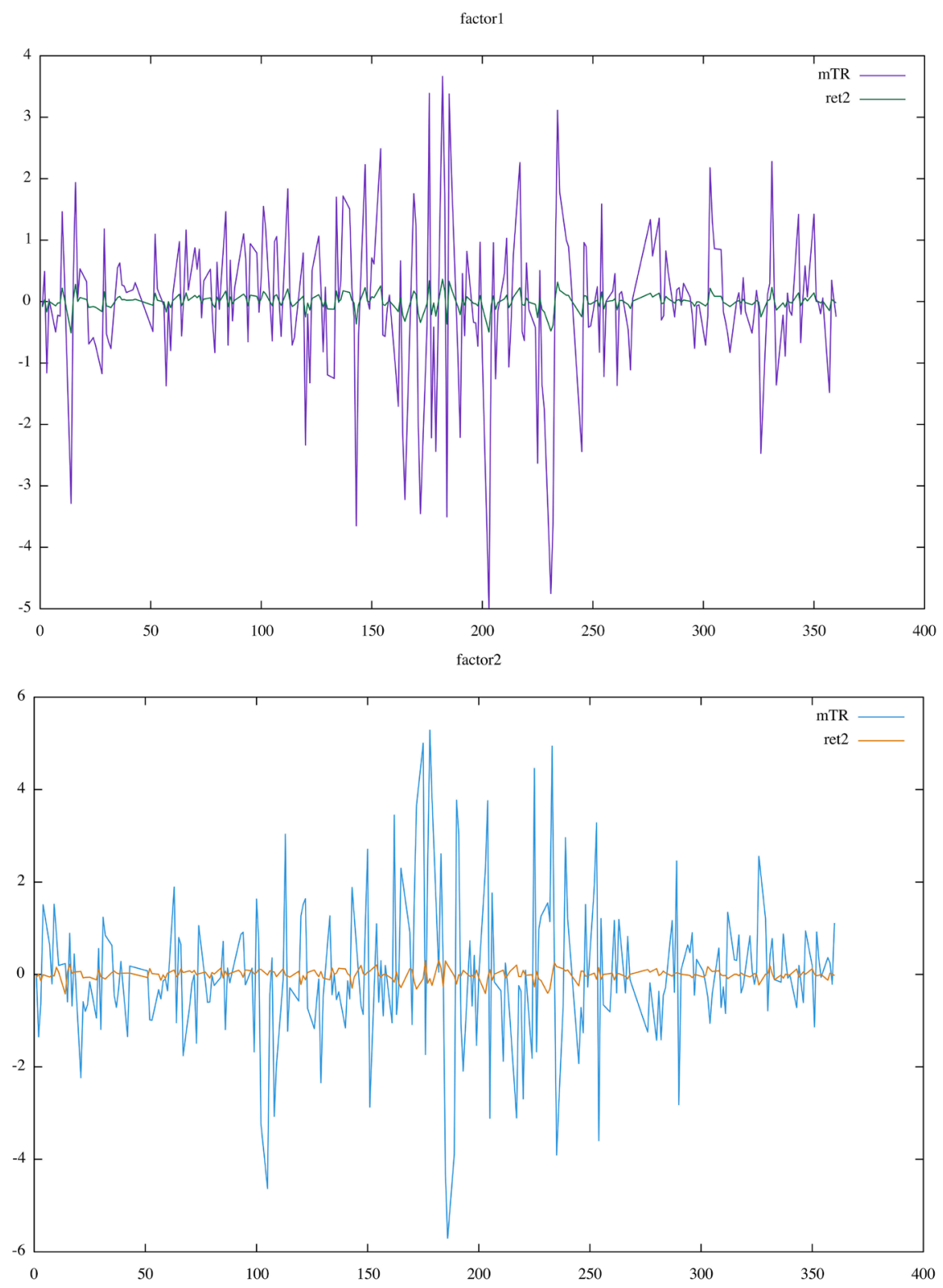

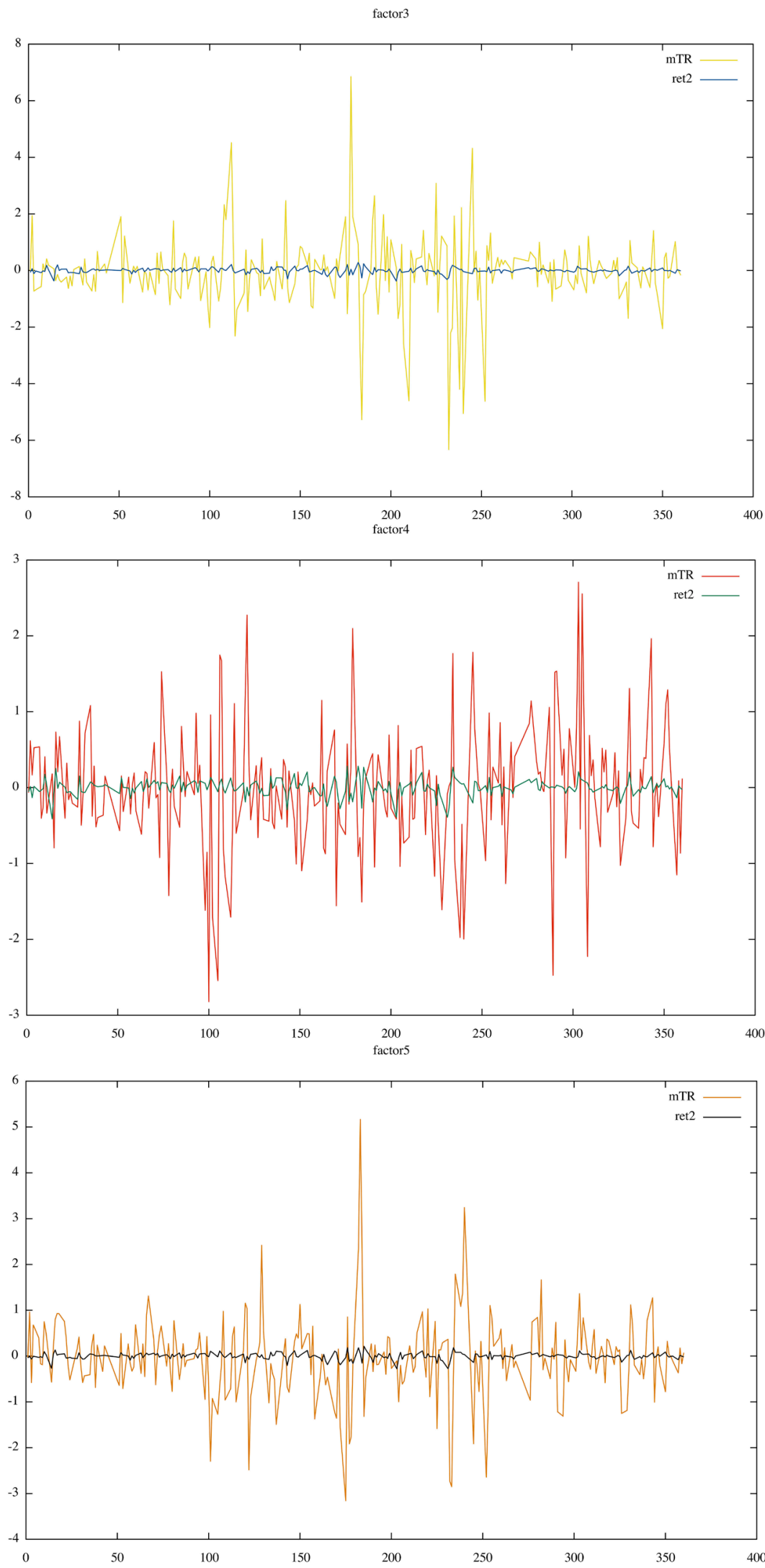

Figure 3. Scatter plots of logarithmic gains in the context of actual returns and risk-neutrality. 
In the risk-neutral condition and with the actual logarithmic return rate, the descriptive statistical characteristics of each factor are obtained using SPSS as in Table 3.

Using Equations (26)-(27), we can draw the nonparametric estimation of the Shanghai 50 Index in risk neutrality and actual returns.

Figure 4 shows the nuclear density estimates of the daily logarithmic returns under actual returns and in a risk-neutral world. The horizontal axis of Figure 4 represents the logarithmic returns and the ordinate represents the number of sample points. The value of the bandwidth is given by Equation (27). Ret represents the income diagram of the five principal components in real returns, while mTR represents the income of the five principal components in the risk-neutral world.

Table 3. The statistical characteristics of each principal component.

\begin{tabular}{ccccccc}
\hline & & Factor 1 & Factor 2 & Factor 3 & Factor 4 & Factor 5 \\
\hline \multirow{2}{*}{$\begin{array}{c}\text { Actual } \\
\text { Returns }\end{array}$} & Variance & 0.0995 & 0.0805 & 0.0761 & 0.0676 & 0.0637 \\
& Skewness & -0.3449 & -0.3068 & -0.3487 & -0.2956 & -0.2873 \\
& Kurtosis & 4.2425 & 4.3599 & 4.6308 & 4.1745 & 3.5489 \\
\hline \multirow{2}{*}{$\begin{array}{c}\text { Risk-Neutral } \\
\text { Returns }\end{array}$} & Mean & 0.0828 & 0.0026 & 0.1239 & -0.0583 & 0.0227 \\
& Skewness & 0.3938 & -0.98207 & -0.1357 & 0.73253 & -0.0577 \\
& Kurtosis & 4.9521 & 4.2098 & 1.8152 & 8.0202 & 1.8552
\end{tabular}
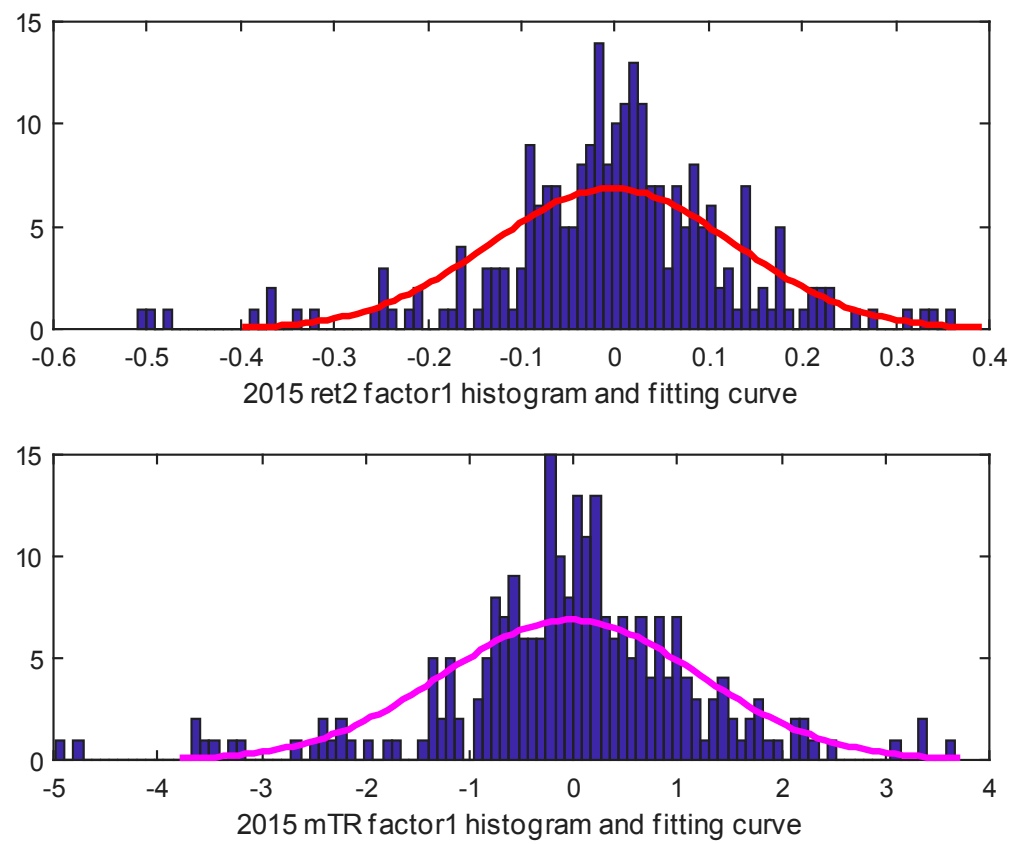

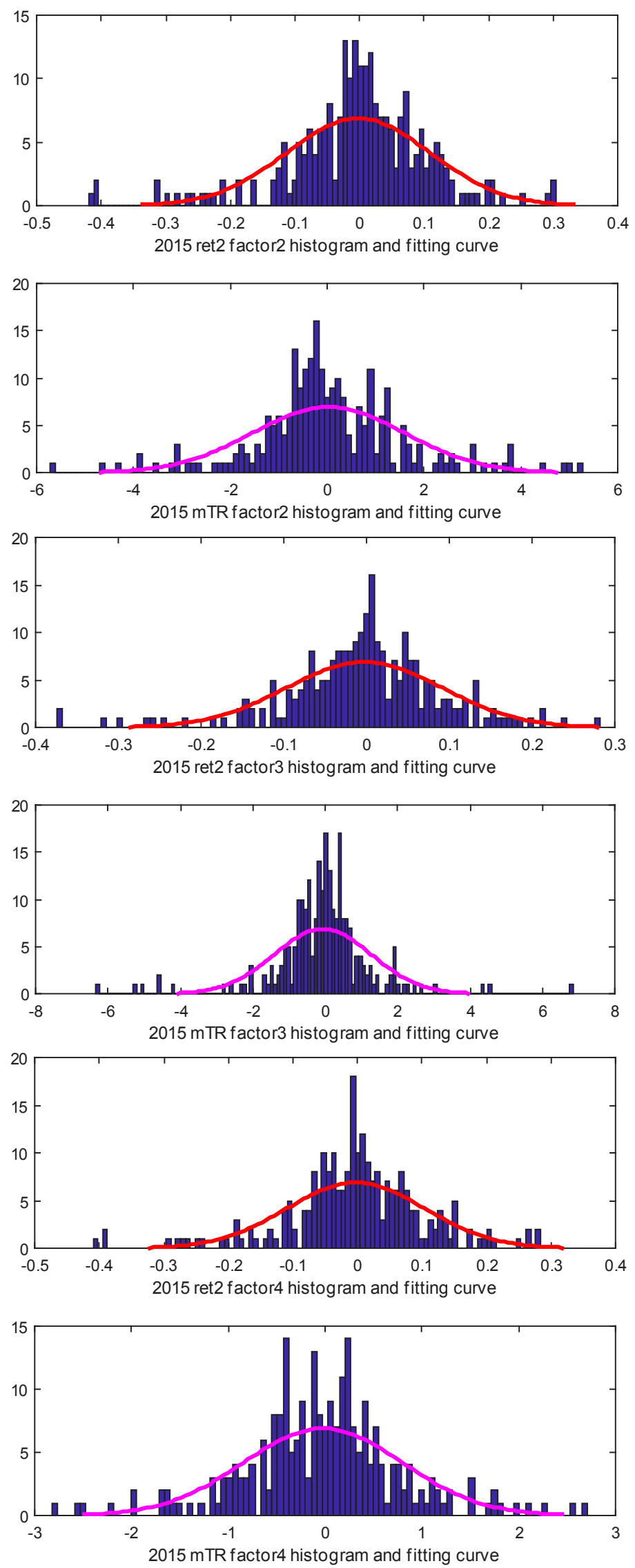

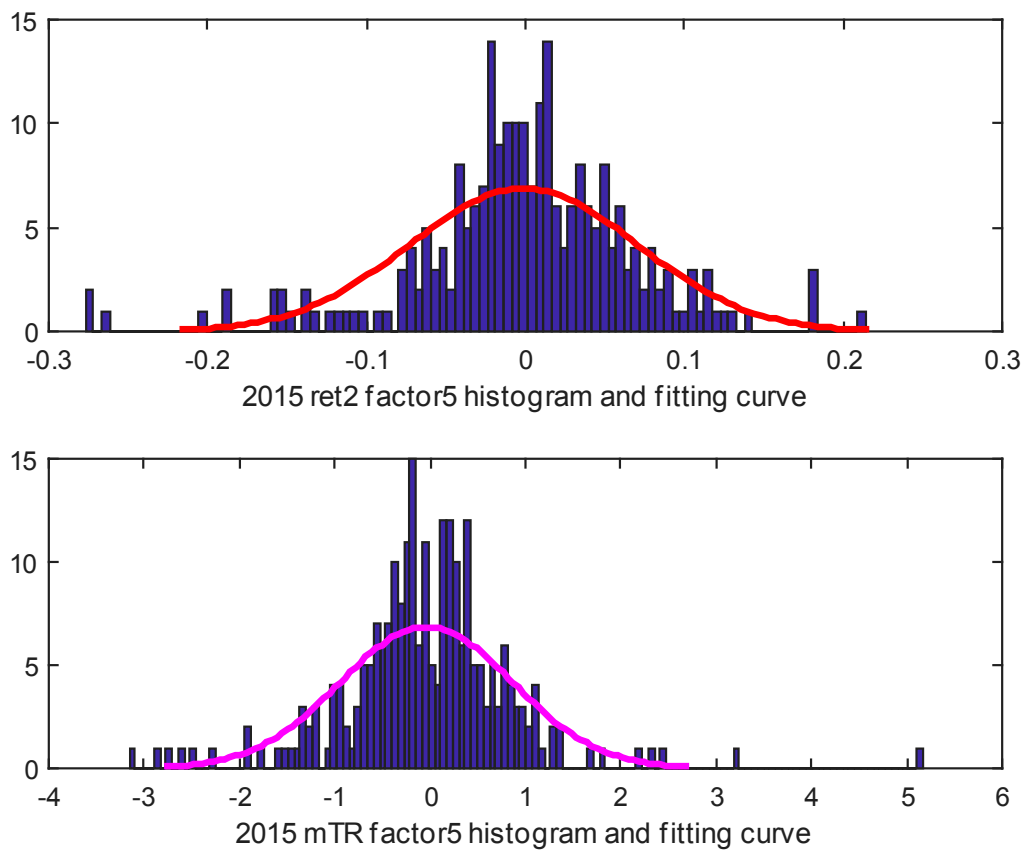

Figure 4. Diagram of nonparametric estimation of risk-neutral and actual data.

Figure 5 is a probability density graph of the nonparametric estimation of actual data and a risk-neutral world. The horizontal axis represents the rate of return, and the vertical axis represents the size of the probability density. The income of the five factors based on the actual data can be seen. The rate is relatively concentrated, and the range of relative and risk-neutral fluctuations is not large. This indicates that the market volatility in 2015 is relatively stable. Then, in the risk-neutral world, the range of rate of return is higher, especially at the left tail where the probability density of returns can be seen as being thicker in the left-biased phenomenon.

\subsubsection{System Risk Comparison in Shanghai Stock Market}

In approximately 2015, China's stock market experienced an extremely low limit of 1000 shares. Therefore, we first compared the results of systemic risk for 2014, 2015, and 2016. Under risk-neutral conditions, the calculation results of the four systemic risk measures are compared, and we compare them from two horizontal dimensions (risk neutrality and actuality) and longitudinally (comparison at different time periods). Moreover, when calculating the MES and SES models, we can set the risk-neutral threshold and the actual benefit threshold to be the same.

Using formula (1), we define $\alpha$ as $5 \%$, and we can obtain a VaR. Using Equation (19), when $R \leq q_{\alpha}$, we can calculate the corresponding $T R_{t}^{i}$ value. The risk-neutral logarithmic gains obtained above and the yields of the five factors based on the actual data are brought into Equations (3)-(5), and Equations (21) and (22) are used to find $T M R_{t}^{i}$ and $T S R_{t}^{i}$. Table 4 shows the system-risk comparison results for China's A-share market during 2014-2016. 

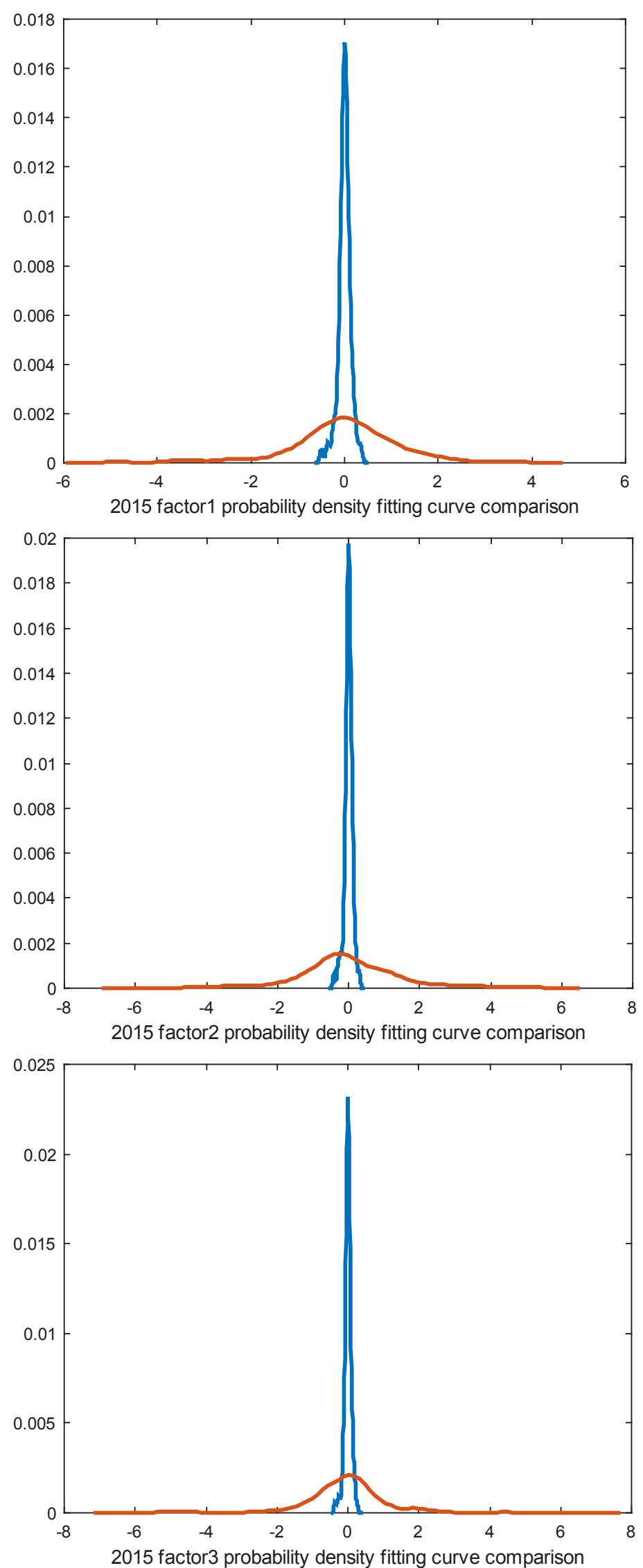

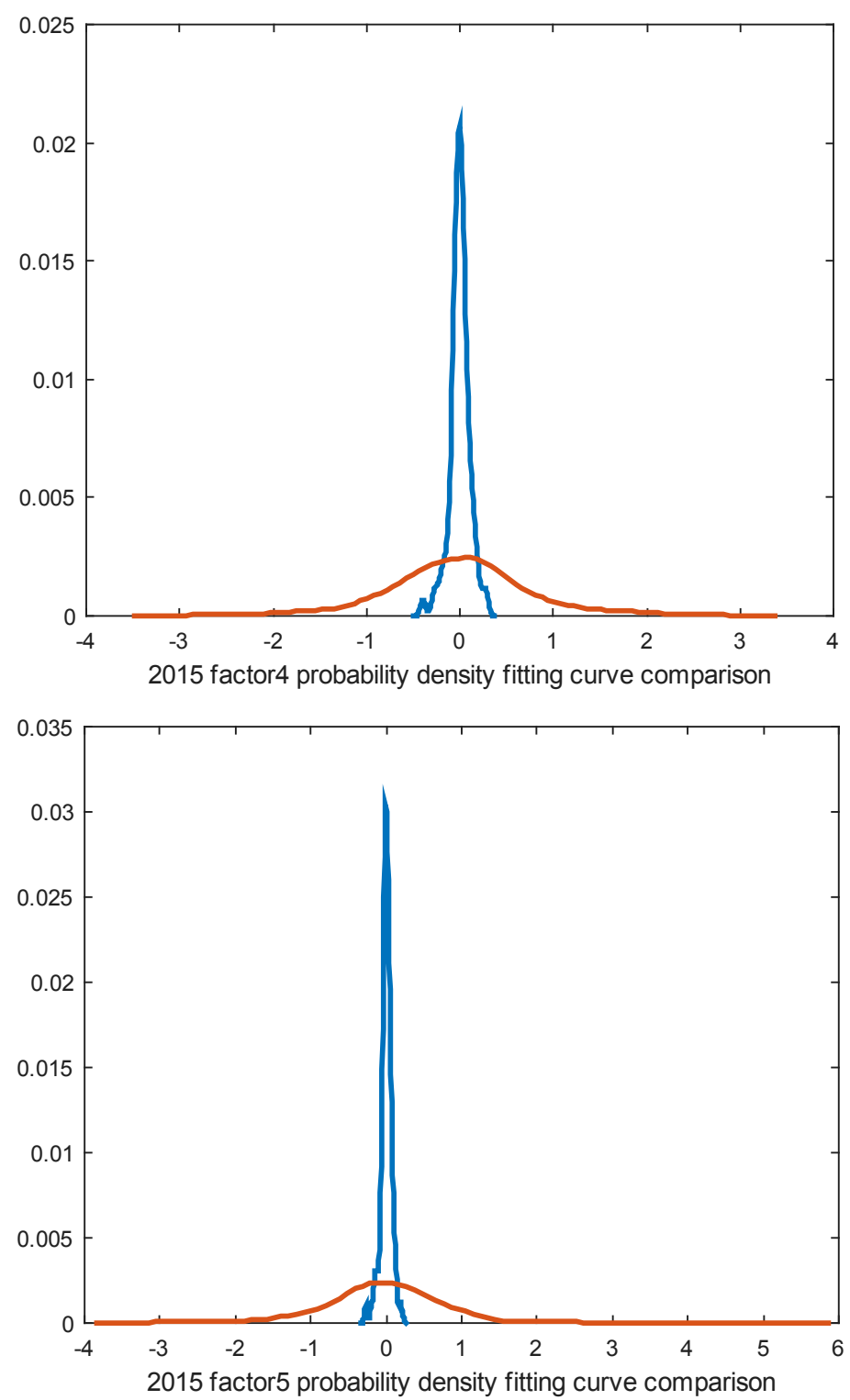

Figure 5. Probability density graph for nonparametric estimation of risk-neutral and actual data.

Table 4. Comparison of the systematic risks from 2014 to 2016.

\begin{tabular}{cccccc}
\hline Year & & VAR & ES & MES & SES \\
\hline \multirow{2}{*}{2014} & Real & -3.3256 & 0.0045 & 0.0045 & 0.3803 \\
& $\begin{array}{c}\text { Risk } \\
\text { Neutral }\end{array}$ & -3.2706 & 0.0099 & 0.3466 & 0.4829 \\
& Real & -3.1382 & 0.0123 & 0.0123 & 0.3899 \\
2015 & Risk & -3.1446 & 0.0083 & 0.3251 & 0.4759 \\
& Neutral & -3.1559 & 0.0207 & 0.0203 & 0.2843 \\
\multirow{2}{*}{2016} & Real & -3.2013 & 0.0072 & 0.2907 & 0.4714 \\
\hline
\end{tabular}


From Table 4, we can find that investors in the risk-neutral world have more enthusiastic reactions in 2014, the risk neutral value under the MES model is 0.3466 , the real value under the MES model is 0.0045 , and the risk neutral value is about 77 times of the real value under. Based on the limited combinations of these 20 stocks, we can see that it contributes to the overall systemic risk. The systemic risk measurement in the risk-neutral world is even stronger, thus indicating that the financial system has also reached a critical state. This also verifies that there has been skyrocketing and slumping trends in the 2015 stock market.

To further study the response of the model to the turbulent market, we compared the risk measures in 12 months of 2015. The results are shown in Figure 6.

As seen from Figure 6, from November 2014 to June 2015, the stock prices show a rising trend, during which the Shanghai Composite Index rose from 2400 to 5178 points, an increase of $115 \%$. During this period, many stocks rose more than 5 times. However, during the 17 trading days from June 15 to July 9, 2015, the stock market continued to plummet, with the Shanghai Index falling by $32 \%$. During the period from May to July, the values of the MES and SES models in the risk-neutral situation showed an upward trend, while the values of the MES, SES, and ES models in the actual stock market showed a declining trend. After the outbreak of systemic risk in June, it began to rise. The systemic risk measures based on the actual stock market have a certain lag.

From August 25 to the end of September of that year, the stock market continued to plummet by 1000 points. There have been several phenomena of the daily limit-down of thousands of stocks. Such a rapid decline has not happened in the past 20 years. It is precisely because of this systemic risk that investors' enthusiasm has decreased. At this time, in the risk-neutral situation, both the MES and SES have a very high value and have a good forecast of systemic risk. However, the value of the MES and SES measured based on the actual market data shows a downward trend. Due to the occurrence of pre-systematic risks, the valuation of the stock price was rapidly reduced, and the financial market reached a critical state and collapsed repeatedly. As a result, investors turned pessimistic about the market. Therefore, the rebound began at the end of September. The value of the MES in risk-neutrality began to gradually decrease. Investors also gradually became optimistic and the valuations became more attractive. Therefore, the market valuation was constantly being repaired. The values of MES and SES continued to show a declining trend and were highly consistent with the changes in the market.

Therefore, through comparison, we can find the following. 1) The measurement of systemic risk under risk-neutrality is more related to actual market changes, and it can more accurately show real market risks. 2) Compared with other three kinds of risk measures, MES is the best systemic risk prediction method, and it has certain early warning characteristics for the occurrence of systemic risks. 
VAR

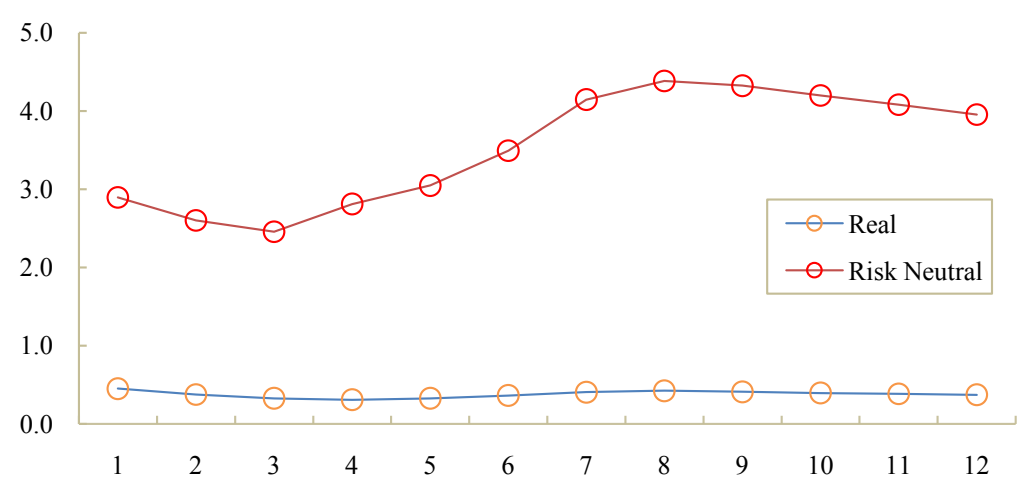

ES
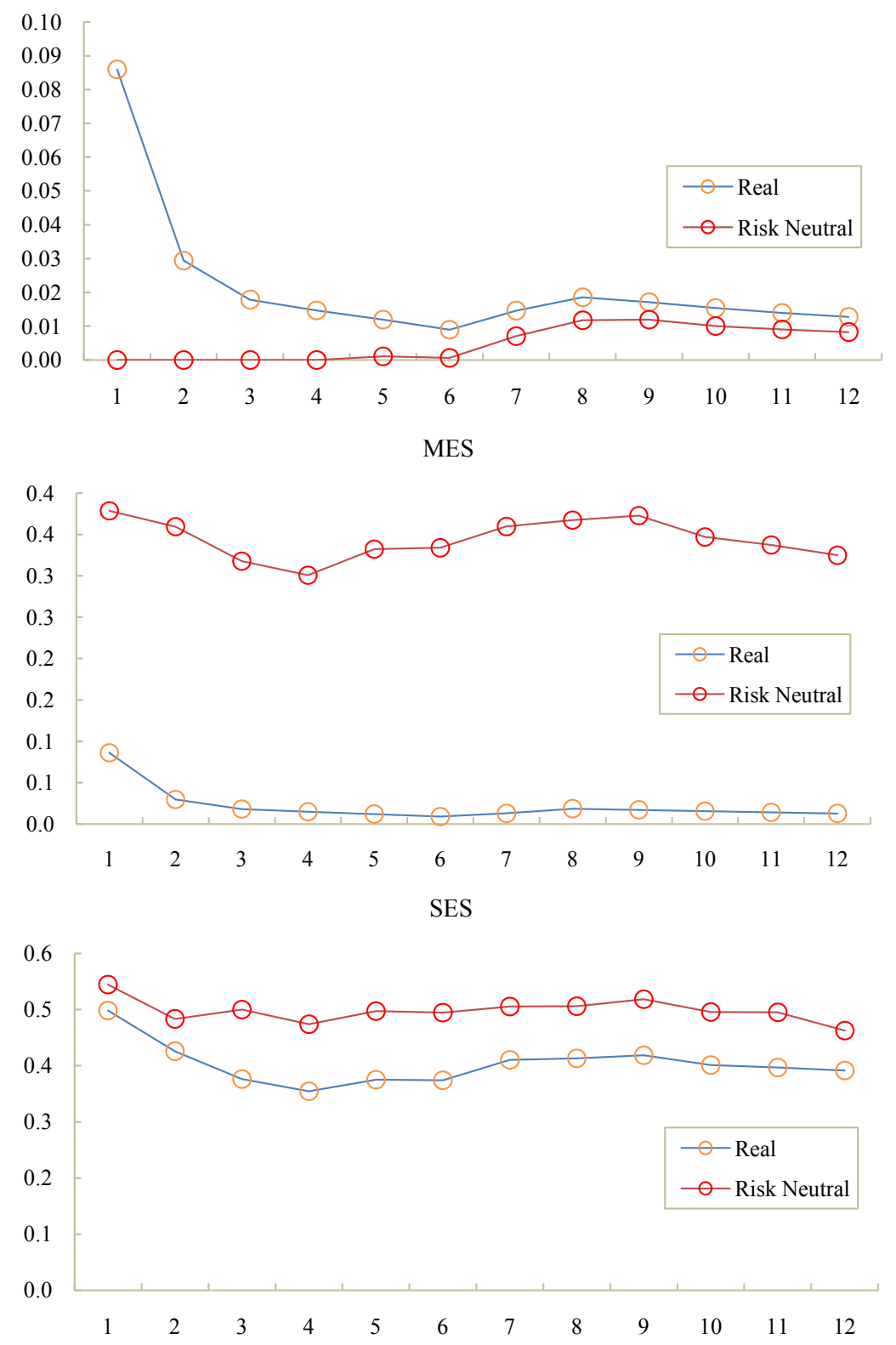

Figure 6. Comparison of four risk measures under actual and risk-neutral conditions. 


\subsection{Empirical Analysis of Hong Kong Stock Market in China}

To test whether the method is universal, we use the Hong Kong stocks Hang Seng Index to test the Hong Kong market in the same way. We remove the stocks that have stalled; we can obtain daily data on 31 stocks as we can see in Table 5.

Figure 7 shows the results of the PCA of the 31 stocks of the Hang Seng Index. The abscissa represents each master. The components, according to the method of principal component analysis, convert the related indicator variables into independent indicator variables. There are a total of 31 stocks with logarithmic gains corresponding to 31 unrelated principal components. The vertical axis represents the explanatory power of each principal component, the rectangle represents the magnitude of the explanatory force of each principal component, and the trapezoid represents the magnitude of the cumulative explanatory force.

According to Figure 7, similar to the Shanghai Stock Index, a factor of $80 \%$ or more of cumulative explanatory power is obtained, which is a total of five factors.

First, the longitudinal comparison of the market before and after the large fluctuations occurred. The A-share market in China experienced a sharp rise and fall in 2015. Therefore, we chose to conduct a vertical comparison from 2014 to 2016 .

Table 5. Names and codes of the 31 constituent stocks of the Hong Kong Hang Seng index.

\begin{tabular}{|c|c|c|c|}
\hline Stock Name & Stock Code & Stock Name & Stock Code \\
\hline Tencent Holdings & 00700.HK & Swire Pacific Corporation & 00019.HK \\
\hline CLP Holdings & 00002.HK & Bank of East Asia & 00023.HK \\
\hline Hong Kong and China Gas & 00003.HK & Galaxy Entertainment & 00027.HK \\
\hline Wharf Group & 00004.HK & Xinhe Real Estate & 00083.HK \\
\hline HSBC Holdings & 00005.HK & Hang Lung Properties & 00101.HK \\
\hline Hang Seng Bank & 00011.HK & Kunlun Energy & 00135.HK \\
\hline Henderson Land & 00012.HK & China Want Want & 00151.HK \\
\hline Sun Hung Kai Properties & 00016.HK & Master Master Holding & 00322.HK \\
\hline $\begin{array}{c}\text { China Petroleum and Chemical } \\
\text { Corporation }\end{array}$ & 00386.HK & Hengan International & 01044.HK \\
\hline Hong Kong Exchange & 00388.HK & Construction Bank & 00939.HK \\
\hline Li \& Fung & 00494.HK & Cathay Pacific & 00293.HK \\
\hline China Overseas Development & 00688.HK & China Offshore Oil & 00883.HK \\
\hline ICBC & 01398.HK & China Resources Power & 00836.HK \\
\hline AIA Insurance & 01299.HK & China Petroleum Shares & 00857.HK \\
\hline China Mobile & 00941.HK & China Shenhua & 01088.HK \\
\hline China Unicom & 00762.HK & & \\
\hline
\end{tabular}




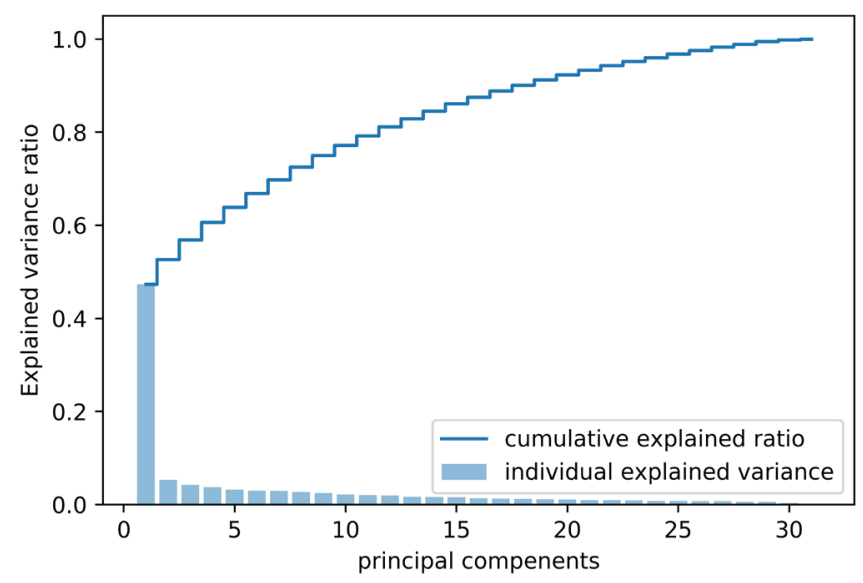

Figure 7. The principal component graph of the logarithmic daily returns of the Hang Seng Index.

According to Table 6, during the period from 2014 to 2015, the Hang Seng Index continued to rise until May 2015, and investors' enthusiasm continued to rise. However, after May 2015, the Hang Seng Index dropped from 28,588.52 points to $18,278.80$ points, losing nearly half of the market value and investors' enthusiasm has also significantly declined. This can also explain why the value of the MES based on individual stocks in reflecting the systematic risk contribution is smaller than the MES value of 2014.

Figure 8 shows the 12-month changes of the four system risk indicators that were calculated based on the 31 stocks in the Hong Kong stock market under the real environment and risk-neutrality in 2015.

Under the influence of the central government's successive favorable policies, the Hong Kong stocks have gained momentum in the first half of the year. On June 30 , the Hang Seng Index closed at 26,250 points. The cumulative increase for the six months exceeded $10 \%$. In the first quarter, the Hang Seng Index fluctuated mainly between 24,000 and 25,000. At this time, the risk was decreasing. However, in April, in order to strengthen the Mainland's succession, the government launched measures to strengthen the interconnection and interflow between the two stock markets, including the possibility that mainland public funds can buy Hong Kong stocks through the Shanghai-Hong Kong Stock Connect, Mainland insurance funds can invest in Hong Kong stock shares, and there are some mutual funds authorized for mutual recognition between the Mainland and Hong Kong. The peak in the first half of the year appeared on April 27, and the Hang Seng Index closed at 28,588 points, the highest in more than seven years. From the end of March to the end of May, the stock prices have been showing a rising trend. Under the risk-neutral condition, we can see that VAR, ES, MES, and SES have been showing a rising trend, indicating that systemic risks are also rising. Starting in May, the market began to decline. At this time, the risks of the system continued to rise. However, we can see that the systematic risks measured based on actual data from the beginning of May to the end of June are decreasing, which is different from the actual situation. 
VAR
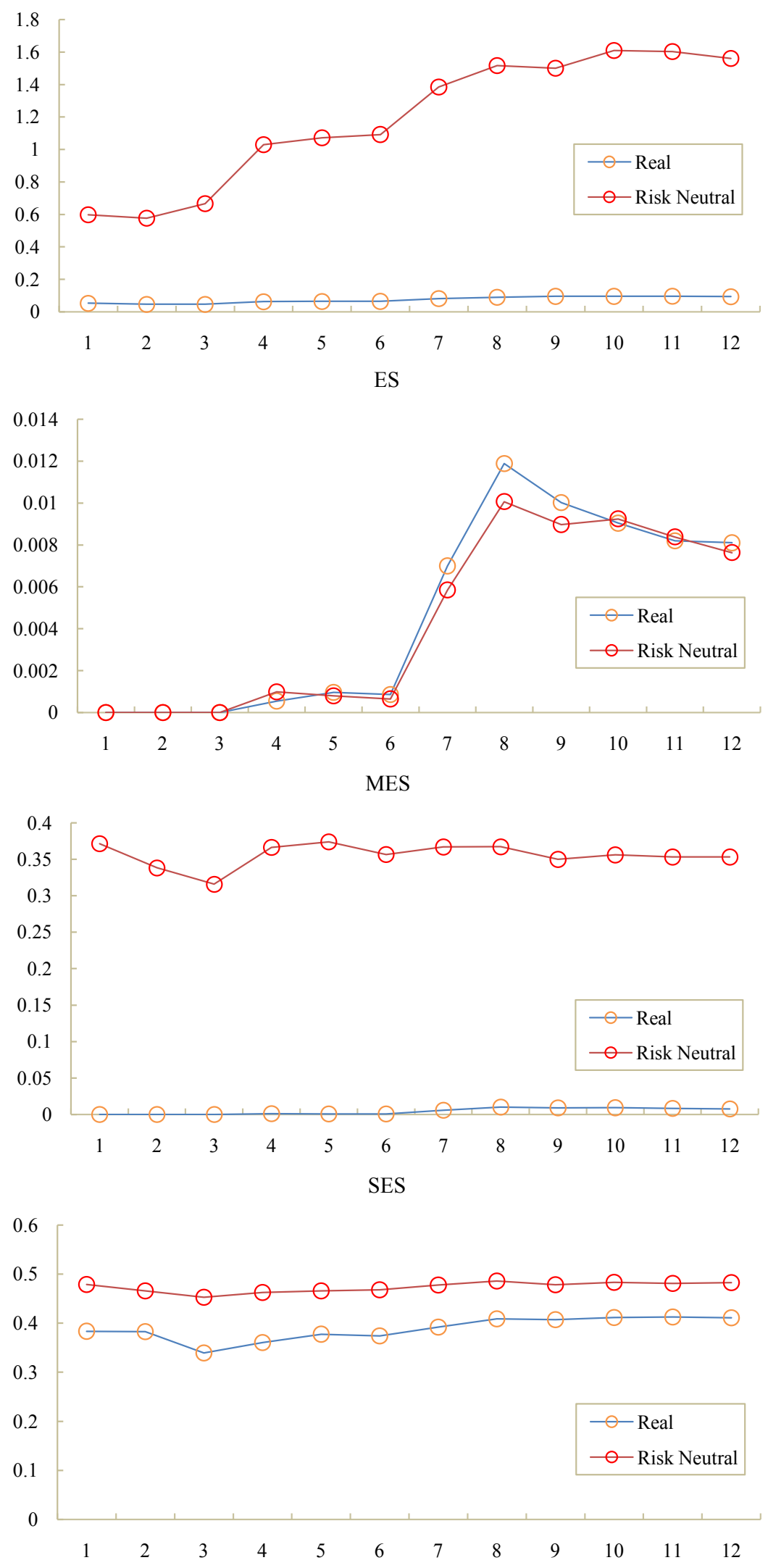

Figure 8. Comparison of the four risk measures under actual and risk-neutral conditions. 
Table 6. Comparison of risk estimation methods of several nonparametric nuclear estimates.

\begin{tabular}{cccccc}
\hline Year & & VAR & ES & MES & SES \\
\hline \multirow{2}{*}{2014} & Real & -3.1755 & 0.0007 & 0.0007 & 0.3849 \\
& Risk Neutral & -2.8682 & 0.0015 & 0.4057 & 0.4946 \\
\hline \multirow{2}{*}{2015} & Real & -3.1223 & 0.0081 & 0.0081 & 0.3947 \\
& Risk Neutral & -3.2038 & 0.0076 & 0.353 & 0.5032 \\
\hline \multirow{2}{*}{2016} & Real & -3.189 & 0.0005 & 0.0005 & 0.2401 \\
& Risk Neutral & -3.141 & 0.0014 & 0.4964 & 0.5002 \\
\hline
\end{tabular}

On July 8, 2015, the Hong Kong stock market collapsed. It once fell more than 2100 points and tumbled to 23,000 points during the session. There was a $5.84 \%$ decline (1458 points) to close, the largest single-day decline since October 27, 2008. The values of the MES and SES in the risk-neutral measurement were not much in this period because our model has already measured systemic risk before. At the end of September, the Hang Seng Index hit its lowest point of 2015 at 20,368.12. At this time, investor enthusiasm gradually decreased, and the market was weak.

At this point, beginning in October, with the influence of internal and external factors such as the Fed's rate hike, the RMB basket and other internal and external factors, the Hong Kong market accelerated rapidly. At the end of December 2015, it broke the 22,000 mark. The trend of changes in risk-neutrality and actual data on systemic risk is consistent with both rising.

\section{Conclusions}

Based on stochastic discount factor theory, we proposed a new method to calculate the financial system risk measurement under risk-neutral conditions, namely, VaR, ES, MES and SES. Then, using these systemic risk measures, we empirically analyzed the changes in the systemic risks of the Chinese stock market and the Hong Kong stock market from 2014 to 2016. Our empirical results show that in the period of the systemic risk of market crashes occurring in both markets in 2015, the risk-neutral systemic risk measures based on stochastic discount factor theory are clearly superior to traditional systemic risk measures. Furthermore, the change of the risk-neutral systemic risk measurement precedes the change of market actual systemic risk. That is, it has a certain early warning for the systematic risk of the financial market. This shows that risk-neutral systemic risk measures have more advantages in managing systemic risks.

In the future, if we want to claim that the change of the risk-neutral systemic risk measurement precedes the change of market actual systemic risk, we need to denefit what a period of systemic risk is and we have to use early-warning models to claim that these two risk-neutral systemic risk measures are good predictors of systemic crisis, so we can use this model to establish a daily time series 
with minute data to construct a daily risk prediction value and achieve a daily risk measurement system based on high-frequency data to better perform forecasting and management of financial systemic risks.

\section{Acknowledgements}

The authors would like to thank the anonymous referees for helpful comments and suggestions, which have led to significant improvements of the present paper.

\section{Conflicts of Interest}

The authors declare no conflicts of interest regarding the publication of this paper.

\section{References}

[1] Bates, D.S. (1991) The Crash of 87: Was It Expected? The Evidence from Options Markets. Journal of Finance, 46, 1009-1044. https://doi.org/10.1111/j.1540-6261.1991.tb03775.x

[2] Bates, D.S. (2000) Post-87 Crash Fears in the S\&P 500 Futures Option Market. Journal of Econometrics, 94, 181-238. https://doi.org/10.1016/S0304-4076(99)00021-4

[3] Pan, J. (2002) The Jump-Risk Premia Implicit in Options: Evidence from an Integrated Time-Series Study. Journal of Financial Economics, 63, 3-50. https://doi.org/10.1016/S0304-405X(01)00088-5

[4] Artzner, P., Delbaen, F., Eber, J.M. and Heath, D. (1999) Coherent Risk Measures. Mathematical Finance, 9, 203-228. https://doi.org/10.1111/1467-9965.00068

[5] Acharya, V.V., Engle, R. and Richardson, M. (2012) Capital Shortfall: A New Approach to Ranking and Regulating Systemic Risks. American Economic Review, 102, 59-64. https://doi.org/10.1257/aer.102.3.59

[6] Adrian, T. and Brunnermeier, M. (2016) CoVaR. American Economic Review, 106, 1705-1741. https://doi.org/10.1257/aer.20120555

[7] Acharya, V., Santos, J. and Yorulmazer, T. (2010) Systemic Risk and Deposit Insurance Premiums. Economic Policy Review, Federal Reserve Bank of New York. https://ideas.repec.org/a/fip/fednep/y2010iaugp89-99nv.16no.1.html https://www.newyorkfed.org/medialibrary/media/research/epr/10v16n1/1008yoru.p df

[8] Brownlees, C.T. and Engle, R. (2010) Volatility, Correlation and Tails for Systemic Risk Measurement. Mimeo, New York University, New York.

[9] Jon, D. and de Vries, C.G. (1997) Tail Index and Quantile Estimation with Very High Frequency Data. https://doi.org/10.1016/S0927-5398(97)00008-X

[10] McNeil, F.R. (2002) A VaR and Expected Shortfall in Portfolios of Dependent Credit Risks. Journal of Banking and Finance, 26, 1317-1334. https://doi.org/10.1016/S0378-4266(02)00265-0

[11] Cai, Z.W. and Xian, W. (2008) Nonparametric Estimation of Conditional VAR and Expected Shortfall. Journal of Econometrics, 147, 120-130. https://doi.org/10.1016/j.jeconom.2008.09.005

[12] Taylor, J.W. (2008) Estimating Value at Risk and Expected Shortfalls Using expecte- 
iles. Journal of Financial Econometrics, 6, 231-252.

https://doi.org/10.1093/jjfinec/nbn001

[13] Cui, X.T., Zhu, S.S., Sun, X.L. and Duan, L. (2013) Nonlinear Portfolio Selection Approximate Parametric Value-at-Risk. Journal of Banking and Finance, 37, 2124-2139. https://doi.org/10.1016/j.jbankfin.2013.01.036

[14] Cui, X.T., Sun, X.L. and Zhu, S.S. (2018) Portfolio Optimization with Nonparametric Value at Risk: A Block Coordinate Descent Method. INFORMS Journal on Computing, 30. https://doi.org/10.1287/ijoc.2017.0793

[15] Ait-Sahalia, Y. and Lo, A.W. (1998) Nonparametric Estimation of State-Price Densities Implicit in Financial Asset Prices. Journal of Finance, 53, 499-547. https://doi.org/10.1111/0022-1082.215228

[16] Ait-Sahalia, Y. and Lo, A.W. (2000) Nonparametric Risk Management and Implied Risk Aversion. Journal of Econometrics, 94, 9-51. https://doi.org/10.1016/S0304-4076(99)00016-0

[17] Bollerslev, T. and Todorov, V. (2011) Tails, Fears, and Risk Premia. Journal of Finance, 66, 2165-2211. https://doi.org/10.1111/j.1540-6261.2011.01695.x

[18] Bollerslev, T., Todorov, V. and Xu, L. (2015) Tail Risk Premia and Return Predictability. Journal of Financial Economics, 118, 113-134. https://doi.org/10.1016/j.jfineco.2015.02.010

[19] Bali, T.G., Cakici, N. and Chabi-Yo, F. (2011) A Generalized Measure of Riskiness. Management Science, 57, 1406-1423. https://doi.org/10.1287/mnsc.1110.1373

[20] Siriwardane, E. (2013) The Probability of Rare Disasters: Estimation and Implications. Technical Report, NYU Stern School of Business.

[21] Almeida, C., Ardison, K., Garcia, R. and Vicente, J. (2017) Nonparametric Tail Risk, Stock Returns and the Macroeconomy. Journal of Financial Econometrics, 15, 333-376. https://doi.org/10.1093/jjfinec/nbx007

[22] Li, Q. and Jeffrey, S. (2007) Nonparametric Econometrics: Theory and Practice. Princeton University Press, Princeton. 